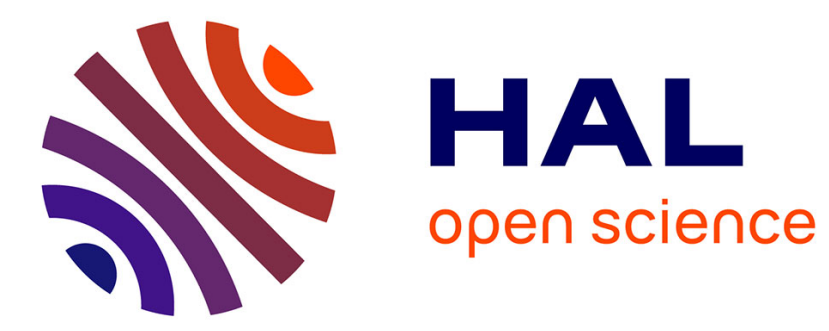

\title{
VHDL-AMS to support DAE-PDE coupling and multilevel modeling
}

Abir Rezgui, Laurent Gerbaud, Benoît Delinchant

\section{To cite this version:}

Abir Rezgui, Laurent Gerbaud, Benoît Delinchant. VHDL-AMS to support DAE-PDE coupling and multilevel modeling. COMPUMAG 2011, Jul 2011, Sydney, Australia. hal-00611013

\section{HAL Id: hal-00611013 \\ https://hal.science/hal-00611013}

Submitted on 21 Jan 2019

HAL is a multi-disciplinary open access archive for the deposit and dissemination of scientific research documents, whether they are published or not. The documents may come from teaching and research institutions in France or abroad, or from public or private research centers.
L'archive ouverte pluridisciplinaire HAL, est destinée au dépôt et à la diffusion de documents scientifiques de niveau recherche, publiés ou non, émanant des établissements d'enseignement et de recherche français ou étrangers, des laboratoires publics ou privés. 


\title{
VHDL-AMS to support DAE-PDE coupling and multilevel modeling
}

\author{
A. Rezgui, L. Gerbaud, B. Delinchant \\ Grenoble Electrical Engineering lab \\ BP 46, 38402 Saint-Martin d'Hères, France \\ Abir.Rezgui@g2elab.grenoble-inp.fr
}

\begin{abstract}
With the increasingly high level of electrical system integration, the modeling of both the system behavior, and the detailed physics of its elements becomes necessary. VHDL-AMS language allows to describe a range of physical systems, such as electro-magnetic devices, using a unified design approach to simulate a complete system. In the paper, the behavioral modeling of multiple energy domains is achieved using VHDL-AMS. This illustrated how the interactions between domains take place with an electromagnetic actuator. Then, a multi-level hierarchical modeling methodology, using a V-shaped-based design approach, allows functional modeling, structural behavioral modeling and detailed component modeling.
\end{abstract}

Index terms - VHDL-AMS, 2D magneto static, PDE-DAE, V shaped Cycle, Multi-domain simulation, multilevel modeling

\section{INTRODUCTION}

The emergence of the modeling language VHDL-AMS, defined by IEEE 1076.1 standard [1] has proved extremely useful for the defining and modeling of multi physical and multi-technological systems. VHDL-AMS is a powerful hardware description language that allows the modeling of the behavior of mixed-signal (analog and digital), the multiphysics systems such as electrical, magnetic, thermal, and so on, as well as the hierarchical modeling of complex multi-physical systems and phenomena [1], [1].

It specifies the possibility to describe the behavior of a complex system by formulating directly the corresponding differential algebraic equations (DAE) of the system, and thanks to its standard language in terms of syntax and semantics, it ensures portable descriptions among different industrial simulators (Portunus $^{\mathrm{TM}}$, SMASH $^{\mathrm{TM}}$, Simplorer $\left.{ }^{\mathrm{TM}} . ..\right)$. Due to their complexity, partial differential equations (PDE) have been intentionally left out in VHDLAMS language. This limits the accurate modeling of system blocks that include physics effects. Various approaches to solve PDE models [3] or to extend VHDL-AMS standard are proposed [4].

The paper deals with the simulation of systems by coupling VHDL-AMS models and others models based on "black box" components. In the approach, a VHDL-AMS model calls external models. This approach should assure the interoperability between models, and should offer, to the designer, the possibility to use VHDL-AMS as a system description language integrating many modeling aspects.

Our approach is applied on a classical E-shaped actuator with a coil bounded to its central leg. It shows how to model such a system by invoking the multi physical aspects and the multi-level modeling of VHDL-AMS.

\section{COUPLING WITH VHDL-AMS}

Since engineering often has to deal with optimization, some models come as functional descriptions which are not coded in a conventional description language (like VHDL-AMS) but rather in pure programming languages such as $\mathrm{C} / \mathrm{C}++$. To implement our approach, two schemes for the coupling of models can be defined:

- coupling using a language: VHDL-AMS provides a "foreign" attribute to decorate functions [1].

- coupling using simulation environment functionalities.

\section{A. Foreign VHDL-AMS keyword}

A first coupling approach is possible thanks to VHDL-AMS "FOREIGN" attribute [1][5]. Fig. 1 shows the principle of this approach to integrate $\mathrm{C}$ functions in VHDL-AMS models. Basically, $\mathrm{C} / \mathrm{C}++$ models or dynamic linked library (DLL) are shown as external functions by the VHDL-AMS model, and allow an exchange of data [5]. Then, if more complex algorithms are required for calculation, software components can be used thanks to "Interface Adapter" ensuring the communication with attribute "foreign".

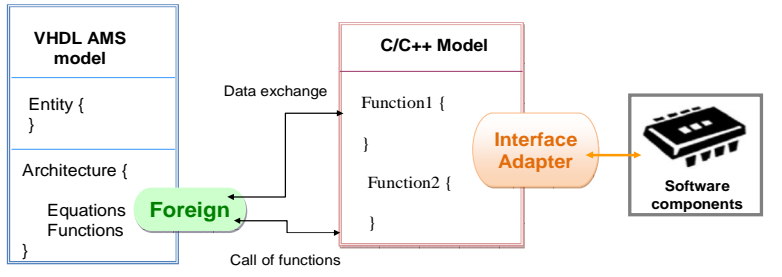

Fig. 1 : Coupling approach using "foreign" attribute

\section{B. Interfacing Solver with Programming Language}

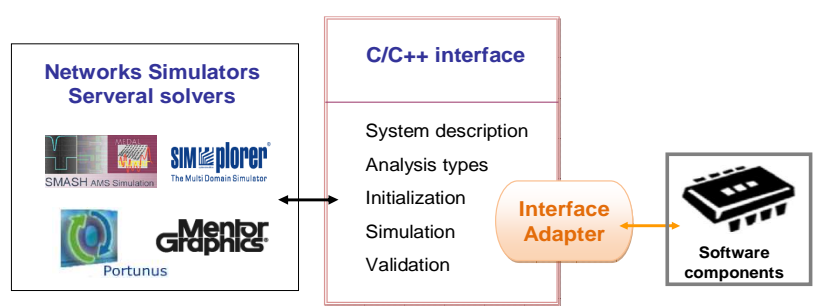

Fig. 2 : Coupling approach using $\mathrm{C}$ communication interface

Fig. 2 shows the principle of the second approach. Many simulators provide a powerful $\mathrm{C}$ communication interface which allows dynamic data exchange between VHDL-AMS models and external models or applications on the same simulator. This offers the possibility to create new models or to encapsulate a fine modeling of subsystems using the programming language $\mathrm{C} / \mathrm{C}++$. Implementing models using the $\mathrm{C}$-interface is helpful if the model behavior cannot be described by standard models or their combinations within macros models. 


\section{V-SHAPED-BASED MODELING DESIGN CYCLE}

Recent researches, inspired from the classical V-shaped design approach, tend to propose new design methodologies based on functional virtual prototyping (FVP), as developed by Y.Hervé [7], which increases each step of design by model and simulation studies. The subject of our study is to present the advantage to use VHDL-AMS for different modeling level of the same system, and it was carried out using only the classical V-shaped design.

The methodology of modeling by VHDL-AMS contains three modeling description level: "functional", "behavioral and structural" and "physical" [1]:

- "Functional modeling": denoted by «system-level», consists in translating the characteristics of the system resulting from the functional specifications into functions which can be simulated.

- "Structural Behavioral modeling": describes phenomena and interactions like digital-analog one and multidomain interactions.

- "Physical modeling": studies the physical behavior of the device.

The combination of modeling with VHDL-AMS and the Vshaped design approach ensures consistency of physical performance criteria and the potentials of functional performances.

\section{APPLICATION ON AN ELECTROMAGNETIC DEVICE}

\section{A. Description}

Fig. 3 shows a classical E-shaped actuator with a coil bounded to its central leg. Only the linear vertical movement of the moving part of the actuator is possible, which is subject to different damping sources due to viscous damping and translational linear spring.

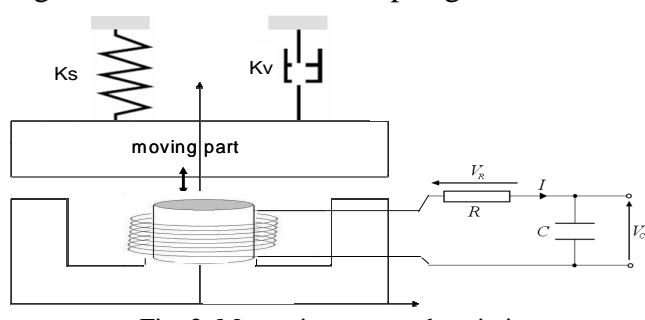

Fig. 3: Magnetic actuator description

\section{B. Modeling}

The dynamic model of the device represents a coupling between the electrical circuit feeding the coil and the mechanical part of the moving part. To model this device, magnetic, electrical and mechanical aspects are carried out by using computation tools with either fine modeling or behavioral modeling.

1) Magnetic: fine modeling using FEM

FLUX2D software was used to model the magnetic force and the inductance value. On the one hand, FLUX2D solver was controlled and linked to the "Foreign" key word $\left(1^{\text {st }}\right.$ method), on the other hand, it was linked to the simulation software ( $2^{\text {nd }}$ method).
2) Magnetic: behavioural modeling using RNM

The modeling of the magnetic behavior of the actuator was made by reluctance network method (RNM) (Fig. 4). For this, a library of all magnetic components, such as linear reluctance, air-gap, magnetic coil, was developed on VHDL-AMS.

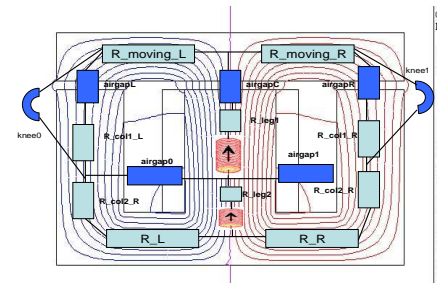

Fig. 4: Reluctance network modelling

\section{3) Electric}

The state system modeling of the electrical circuit feeding the coil was defined by two differential equations. If state variables are $\mathrm{x}$, their derivatives $\mathrm{x}$ 'dot are maximal. The inductance value is provided by the magnetic model.

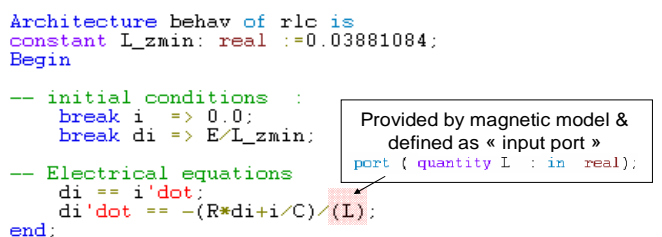

Fig. 5: VHDL-AMS electrical model

4) Mechanic

The state variable of the mechanical part of this system are the core position $\mathrm{z}$, and its velocity v. So, the state system , was defined by two differential equations..

\section{CONCLUSIONS}

VHDL-AMS, as a unified modeling language, has to support all the necessary modeling concepts with mathematically founded semantics and to support multidomain aspects of systems. Using "Foreign" key-word or simulation environment functionalities allow the coupling of VHDL-AMS with PDE solvers or other numerical modeling tools.

The paper demonstrates the use of this functionality in order to do multi-method modeling in order to perform multiphysical and multi-level simulations.

The V-Shaped method will be detailed in the full paper and applied on an E-Core.

\section{REFERENCES}

[1] Norme VHDL-AMS VHDL Analog and Mixed-Signal Extensions, IEEE Standards 1076.1-1999, Mar. 1999.

[2] E.Christen, K.Bakalar, "VHDL-AMS,A Hardware Description Language for Analog and Mixed-Signal Applications", IEEE transactions on circuits and systems, October 1999.

[3] A.B. Abd Rahman "Modelling of Mixed Physical-domain System", Thesis, Faculty of Engineering, September 2010.

[4] Nikitin PV, Shi CR, and Wan B, "Modeling partial differential equations in VHDL-AMS". In Systems-on-Chip Conference, 2003.

[5] SMASH, "Foreign C functions in VHDL-AMS and SPICE models", Release 5.13 - June 2009

[6] J. Turowski, "Reluctance networks," in Computational Magnetics, J. K.Sykulski, Ed. New York: Chapman \& Hall, ch. 4.

[7] Y. Hervé, P.Desgreys, "Functional virtual prototyping design flow and VHDL-AMS”, FDL'06, Septembre 2006, 